\title{
Upponurkka: An Inexpensive Immersive Display for Public VR Installations
}

\author{
Tapio Lokki* Tommi Ilmonen ${ }^{\dagger} \quad$ Wille Mäkelä ${ }^{\ddagger} \quad$ Tapio Takala ${ }^{\S}$ \\ Helsinki University of Technology \\ Telecommunications Software and Multimedia Laboratory
}
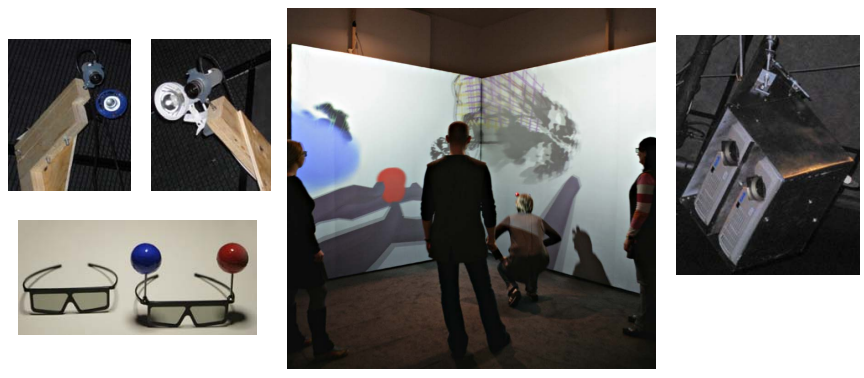

\begin{abstract}
Upponurkka is an inexpensive immersive display system for public virtual reality installations. It is designed for public places to be robust, wireless, and light-weight. The system consists of two passive stereo screens and optical tracking. In this paper the hardware and software of Upponurkka are briefly presented. In addition, experiences of using the system in a public art exhibition are reported.
\end{abstract}

CR Categories: B.4.2 [Hardware]: Input/Output Devices-Image display; J.5 [Computer Applications]: Arts and Humanities-Fine arts

Keywords: virtual reality, immersive display, VR for public

\section{INTRODUCTION}

Upponurkka (literally "a submersible corner" in English) is a lowcost immersive display, especially designed for public VR installations. Like a cave, it is a multi-user display, although only one viewer is tracked so that he/she sees the correct perspective. Special attention in design was paid on the robustness of the system. As a starting point we made a policy decision that from the user perspective the system should be wireless and light-weight.

The motivation for Upponurkka was to build a cost-effective 3D display which could be used in an exposition of immersive art in Kiasma, Museum of Contemporary Art in Helsinki, Finland. The presented immersive art is created by drawing into the air $3 \mathrm{D}$ images with free-hand style in a cave-like environment $[4,5]$. The exhibited artworks are the result of series of studies in which we are seeking an immersive free-hand medium for artists. The immersive art is painted with a special drawing device resembling a data glove, presented in more detail in previous papers $[3,6]$.

\footnotetext{
*e-mail:Tapio.Lokki@tkk.fi

†e-mail:Tommi.Ilmonen@hiit.fi

e-mail:wmakela@tml.hut.fi

§e-mail:Tapio.Takala@tkk.fi
}

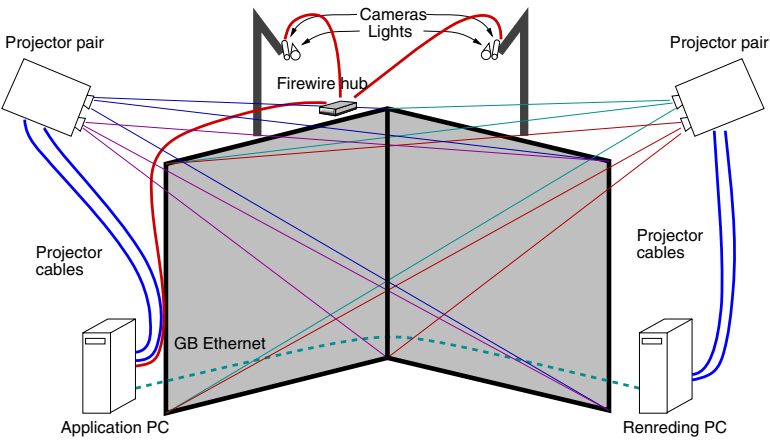

Figure 1: The components of Upponurkka.

\section{EQUiPMENT}

The equipment, both hardware and software, of Upponurkka is completely self-made and constructed from off-the-shelf components. The total cost of all equipment was about $13,000 €$.

\subsection{Hardware}

The schematic illustration of the hardware is depicted in Fig. 1. The projection system consists of four off-the-self LCD projectors equipped with passive polarization filters in front of their lenses, see Fig. 2. In fact, the emitted light from LCD projectors is always polarized. However, in this case the polarization angle was 45 degrees from vertical/horizontal direction and it was practical to rotate the polarizations with the filters to vertical and horizontal direction. Of course, we could have tilted the projectors and manage without the filters (and obtain more luminance), but then the projector rack construction and image adjustment to the screens would have been more complicated. In the current setup, the projectors produce passive stereoscopic images to two $3 \times 3 \mathrm{~m}$ polarization preserving screens which are mounted in right-angle. The projectors are positioned slightly off-center to minimize reflection of the projected light from one screen to the other.

The images are rendered with two PCs, named the application PC and the rendering PC in Fig. 1. Each computer has a single graphics card with dual outputs and both are responsible for render- 


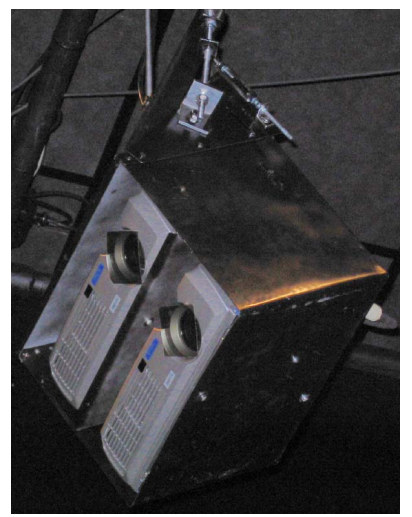

Figure 2: Projectors are mounted to the rack that is hanging from the ceiling.
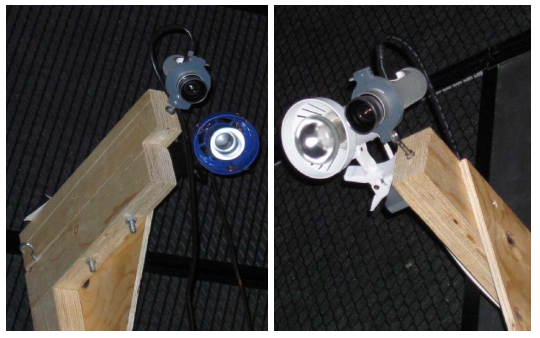

Figure 3: Cameras for motion tracking. To work properly cameras need extra light, produced by ordinary spotlights.

ing 3D content to one pair of projectors. The PCs have integrated 1 GB Ethernet controllers that take care of the communication between PCs.

The tracking of the head of the user is based on custom made optical tracking. The tracking hardware consists of two Apple iSigh FireWire cameras that are equipped with wide-angle converters. They are connected to the application PC via the FireWire hub. In addition, for good performance the tracking needs some extra light which is produced with normal spotlights, mounted as close to the cameras as possible, see Fig. 3. The tracked user is wearing passive stereo-glasses which are equipped with color balls that are covered with retroreflective material, see Fig. 4. Such solution is very inexpensive and robust in public environment.

\subsection{Software}

Upponurkka is run by in-house software on top of the Linux operating system. The graphics to be rendered is distributed to the rendering PC with the Broadcast GL (BGL) [2]. It is an alternative approach for managing graphics clusters. The application using BGL broadcasts binary encoded OpenGL API calls to the rendering slaves over a UDP/IP socket. In Upponurkka the application PC runs the main application and both the application PC and the rendering PC operate as independent rendering slaves. The BGL is very efficient in data-intensive applications that require good scalability to multiple displays.

\subsubsection{Optical Tracking}

Maybe the most interesting innovation in Upponurkka is a cheap optical tracking system. The software is based on the FLUID camera tracking code [1] and it tracks two color balls with two cameras.

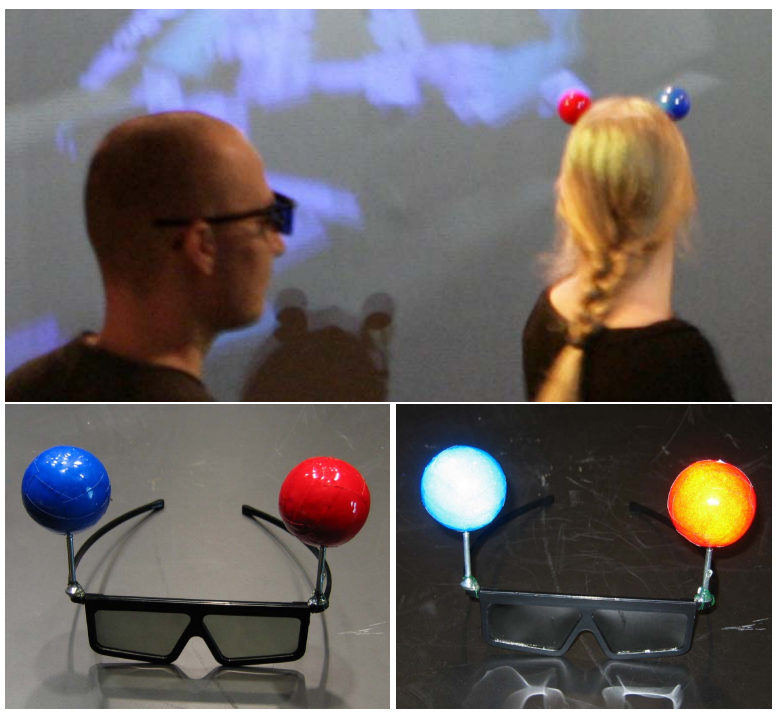

Figure 4: Top: Polarizing stereo glasses in use, one equipped with tracking markers. Bottom: Blue and red retroreflective markers without (on the left) and with (on the right) spotlight illumination.

The tracking is performed with $30 \mathrm{~Hz}$ sampling frequency and it works very well in the viewing area which is about $3 \times 3 \mathrm{~m}$ in front of the screens.

For optical tracking we needed markers that would not be confused with other objects in the room. At first we considered using markers with rare color that would seldom appear in clothes of users. In practice such colors do not exist, since the museum visitors may have any kind of clothing. As a next step we tested how a retroreflective material would work. As seen in Fig. 4 retroreflective markers appear very bright when the spotlight illuminates them. Such illumination is easily obtained by mounting spotlights close to the cameras. As a result the markers can be detected based on two features. First the markers have a well-defined color and second the markers are brighter than any normal objects. In exhibition settings in addition to the markers the only bright objects are the ones with glossy reflection that hits the camera (leather handbags etc.). Such reflections are typically white (regardless of the color of the material) and easy to filter out.

The applied Apple iSight FireWire cameras don't, unfortunately, support the control of the color balance. Therefore, color drift occurs as the cameras adjust their color profile automatically. This problem was overcome by using monochromatic markers (red and blue) - a pure red is pure red, at least green and blue values are close to zero, regardless of the color balance of the camera.

The complete motion tracking pipeline is:

1. Capture images.

2. Detect the markers from the images.

3. Calculate the ray from camera to the marker.

4. Calculate the marker locations from the ray information.

5. Calculate head location from the marker locations.

6. Perform Kalman filtering on the location data to obtain smooth input for graphics rendering.

At each stage we encounter noisy data that needs to be dealt with. For this reason the system implements several ad-hoc error correction/recovery methods on stages $2-4$. 
Table 1: Distribution of exhibition visitors, grouped with time spent watching artworks.

\begin{tabular}{|c|c|c|c|c|c|c|c|}
\hline $\begin{array}{c}\text { user } \\
\text { type }\end{array}$ & $\begin{array}{c}\text { wear } \\
\text { glasses }\end{array}$ & $\begin{array}{c}\text { wear tracked } \\
\text { glasses }\end{array}$ & $\begin{array}{c}\text { pick } \\
\text { a set }\end{array}$ & $\begin{array}{c}\text { main focus: } \\
\text { interface }\end{array}$ & $\begin{array}{c}\text { main focus: } \\
\text { artworks }\end{array}$ & $\begin{array}{c}\text { spent } \\
\text { time }\end{array}$ & $\begin{array}{c}\text { rough } \% \text { of } \\
\text { visitors }\end{array}$ \\
\hline A & - & - & - & + & - & 10 sec & 10 \\
B & + & - & - & + & - & 20 sec & 10 \\
C & + & + & + & + & - & 1 min & 10 \\
D & + & + & + & + & - & $2-5$ min & 40 \\
E & + & + & + & - & + & $10-20$ min & 20 \\
F & $?$ & $?$ & $?$ & $?$ & $?$ & $?$ & 10 \\
\hline
\end{tabular}

\section{Use Case: Immersive Art Exhibition}

Upponurkka was mounted to a separate room in Kiasma, the Museum of Contemporary Art in Helsinki, for a period of three weeks in November 2005. During this time, a few thousand visitors experienced the immersive art exhibition, "Painted into air", by Wille Mäkelä and ten guest professionals of traditional fine art. Fig. 5 is taken in the museum and in Fig. 6 a few sketches are presented. The total of 25 artworks were first painted in the cave-like environment, most of it with the first version of the painting software $[4,5]$. In Kiasma, the 3D paintings were presented automatically one by one, for about a minute each which is close to a normal museum visitor's time per an art work. The paintings were shown in three separate series, following the steps of the painting tool development. When a set ended, the tracked user could pick a new set by walking against one of the three symbol columns. Besides the picking of a set, the user had no other interaction options but walking in the immersive artworks. With such user interface no action buttons or other interaction devices, which attracts the user to game behavior, were needed. Besides, such assessories tend to break down in public VR installations. Naturally, an user guide and a thumbnail map of the artworks were presented on the side walls.

To find out the approximate behavior of the visitors, we saved $\log$ data, such as tracker data, security videos, message interface, and notes. Some people who came to the room when it was empty did not wear either the tracked stereo glasses or the usual ones, just shortly looked at the user interface (stuck columns) on the screen and went out. Some others learned intuitively to use the tracked glasses and saw every single artwork in a row.

Table 1 explains the visitors action in the art exhibition. User types $\mathrm{A}$ and $\mathrm{B}$ are alone and do not find any support. Type $\mathrm{C}$ user has more guts and gets a very interesting and disturbing new experience, withdrawing immediately to smelt it. User in category D is enjoying the interface with an amusement park attitude, walking and diving around, trying to fool the computer with fast runs, very often attracting more people to gather around with normal stereo glasses, even 20 by the same time. Finally, type E user is alone or with a small group, focusing on an aesthetic experience. Approximately, people found it intuitive and very interesting to use the system. Apparently a new user learned to use the system easier if the user came to the room at a moment when somebody was already using the tracked glasses.

The room was mostly without a guarding guide. Still after the three weeks, only five of the 20 polarization glasses were broken, including one pair of target glasses. In spite of little kids jumping against the walls, the silver screens were still in one piece, only a little worn out at the low edge.

\subsection{Discussion}

Scrutinizing the user types A-F suggests that a better support should be given to types A and B. Upponurkka was located in the isolated space in the museum, therefore an individual did not often see any others to use the system. Thus, tacit knowledge about the use of the installation did not flow in the best way. Next time, a more open exhibition space should be considered. An ideal place might be a corner of a large exhibition hall, letting the spectators to have a gradual approach from the periphery to the stereo glass zone and then to the hot spot of the tracked user. For museum personnel, the open solution would ease the task of guiding and guarding. An important condition would then be that all the other installations in the hall should also use dim lights.

People should have understanding about what harms the system. Basically, written warnings are not the way to make clear security rules. The best way is the tacit knowledge coming from other people, either users or museum personnel. A foot list could though be adjusted to protect the low edge of the screens.

\section{Conclusion}

The inexpensive and robust to use immersive display system for VR applications is presented. Both applied hardware and software are overviewed and user experiences are reported. The presented system has been applied in public art exhibition without technical problems. In the exhibition the system run smoothly, without any interruption, for three weeks and people found out intuitively how to operate with an immersive display and deal with other users. This proves that VR applications can be shown also in public places.

\section{REFERENCES}

[1] T. Ilmonen and J. Kontkanen. Software architecture for multimodal user input - FLUID. In The Proceedings of the 7th ERCIM Workshop, pages 223-242, Chantilly, France, October 2002.

[2] T. Ilmonen, M. Reunanen, and P. Kontio. Broadcast GL: An alternative method for distributing OpenGL API calls to multiple rendering slaves. The Journal of WSCG, 13(2):65-72, 2005.

[3] W. Mäkelä. Working 3D meshes and particles with finger tips: Towards an immersive artists' interface. In New Directions in $3 D$ User Interfaces Workshop, IEEE Virtual Reality Conference, pages 77-80, Bonn, Germany, March 122005.

[4] W. Mäkelä and T. Ilmonen. Drawing, painting and sculpting in the air: Development studies about an immersive free-hand interface for artists. In Beyond Wand and Glove Based Interaction Workshop, IEEE Virtual Reality Conference, pages 89-92, Chicago, IL, USA, March 282004.

[5] W. Mäkelä, M. Reunanen, T. Takala, and T. Ilmonen. Possibilities and limitations of immersive free-hand expression: a case study with professional artists. In ACM Multimedia, pages 504-507, New York, NY, USA, October 10-16 2004.

[6] M. Reunanen, K. Palovuori, T. Ilmonen, and W. Mäkelä. Affordable fingertip tracking with ultrasound. In Virtual Environments 2005, Eurographics/ACM SIGGRAPH Symposium Proceedings, pages 51-58, Aalborg, Denmark, October 6-7 2005. 


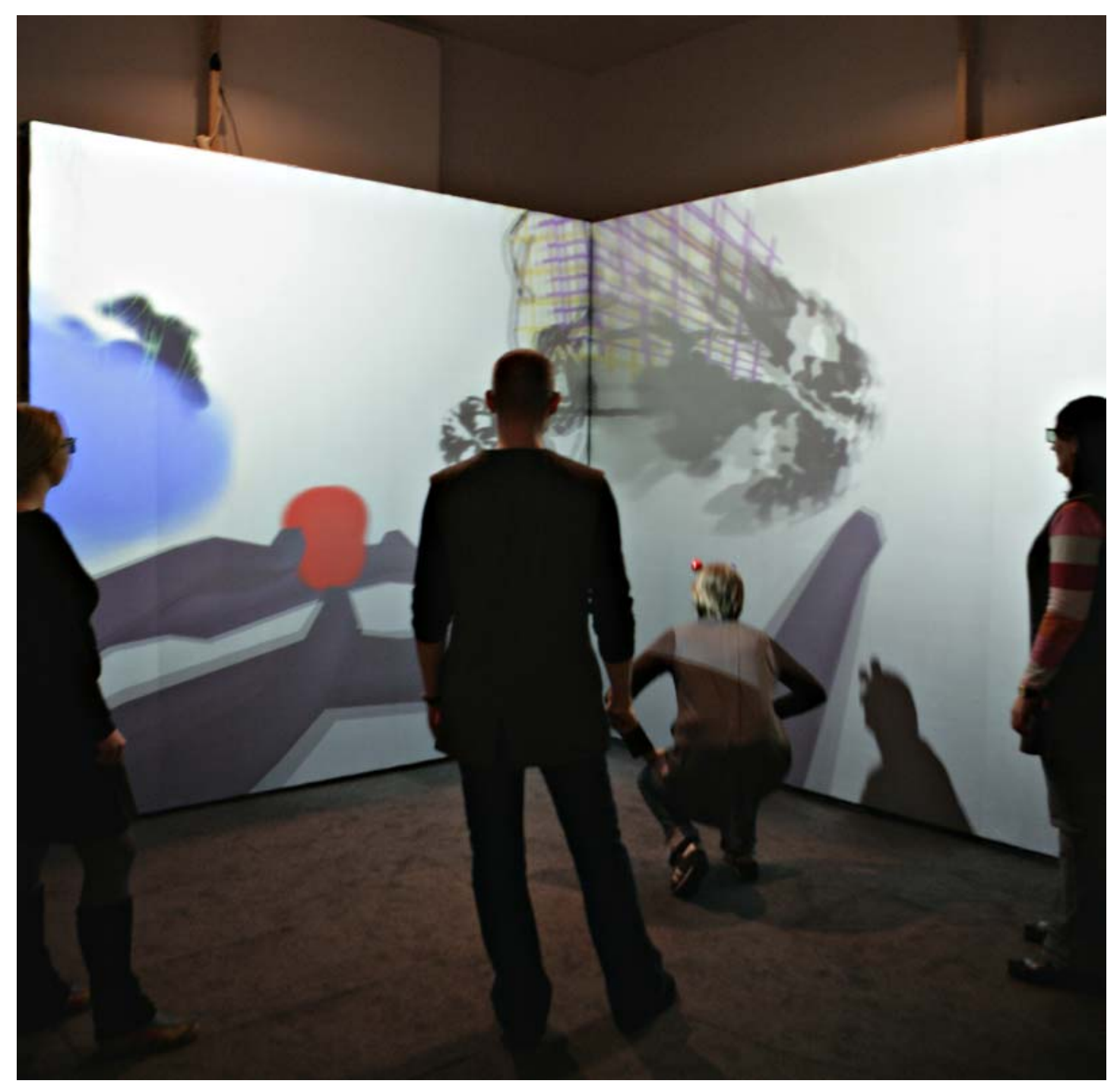

Figure 5: Upponurkka in action in Kiasma, Museum of Contemporary Art in Helsinki.
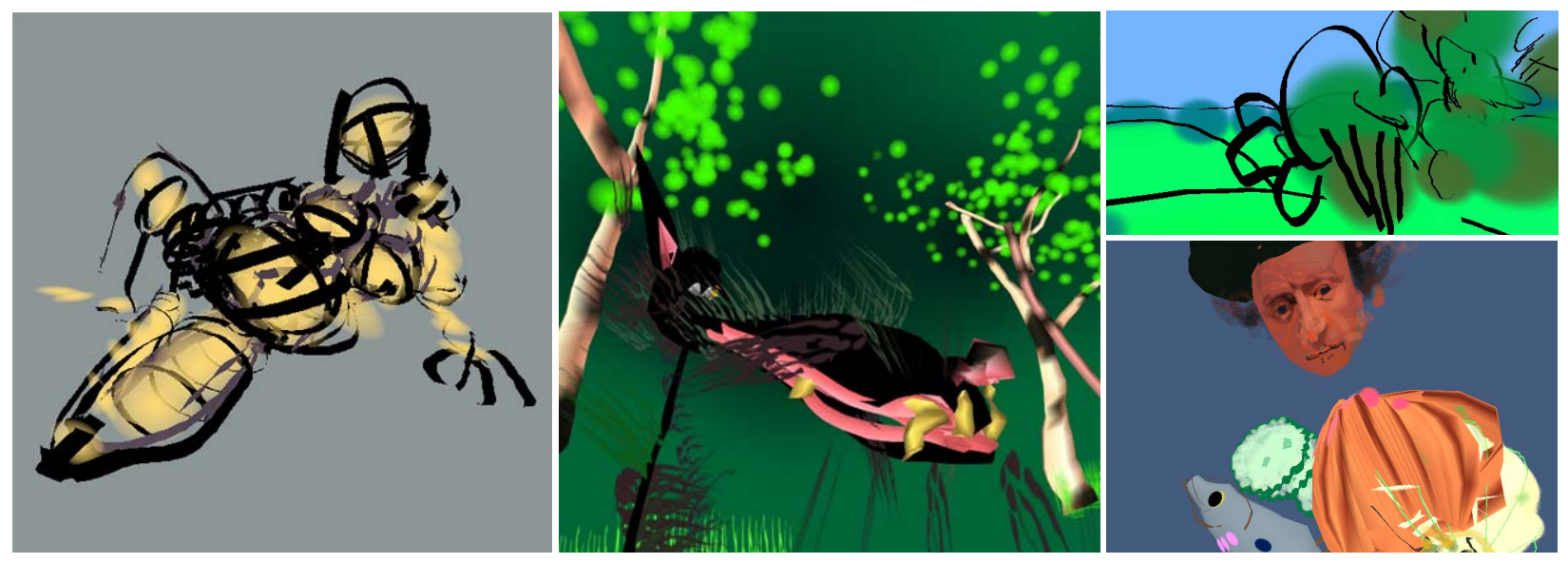

Figure 6: A few example sketches painted in the air by Wille Mäkelä. 